\title{
Evidence for lung repair and regeneration in humans: key stem cells and therapeutic functions of fibroblast growth factors
}

\author{
Xuran $\mathrm{Chu}^{1,4}$, Chengshui $\mathrm{Chen}^{2}$, Chaolei $\mathrm{Chen}^{2}$, Jin-San Zhang ${ }^{1,2,3}$, Saverio Bellusci $(\varangle)^{2,3,4}$, Xiaokun Li $(\varangle)^{1}$ \\ ${ }^{1}$ School of Pharmaceutical Sciences, Wenzhou Medical University, Wenzhou 325035, China; ${ }^{2}$ Laboratory of Interventional Pulmonology of \\ Zhejiang Province, Department of Pulmonary and Critical Care Medicine, The First Affiliated Hospital of Wenzhou Medical University, \\ Wenzhou 325000, China; ${ }^{3}$ Institute of Life Sciences, Wenzhou University, Wenzhou 325035, China; ${ }^{4}$ Cardio-Pulmonary Institute, Universities \\ of Giessen and Marburg Lung Center, member of the German Center for Lung Research, Justus-Liebig-University Giessen, 35392 Giessen, \\ Germany
}

(C) Higher Education Press and Springer-Verlag GmbH Germany, part of Springer Nature 2019

\begin{abstract}
Regeneration carries the idea of regrowing partially or completely a missing organ. Repair, on the other hand, allows restoring the function of an existing but failing organ. The recognition that human lungs can both repair and regenerate is quite novel, the concept has not been widely used to treat patients. We present evidence that the human adult lung does repair and regenerate and introduce different ways to harness this power. Various types of lung stem cells are capable of proliferating and differentiating upon injury driving the repair/regeneration process. Injury models, primarily in mice, combined with lineage tracing studies, have allowed the identification of these important cells. Some of these cells, such as basal cells, broncho-alveolar stem cells, and alveolar type 2 cells, rely on fibroblast growth factor (FGF) signaling for their survival, proliferation and/or differentiation. While preclinical studies have shown the therapeutic benefits of FGFs, a recent clinical trial for acute respiratory distress syndrome (ARDS) using intravenous injection of FGF7 did not report the expected beneficial effects. We discuss the potential reasons for these negative results and propose the rationale for new approaches for future clinical trials, such as delivery of FGFs to the damaged lungs through efficient inhalation systems, which may be more promising than systemic exposure to FGFs. While this change in the administration route presents a challenge, the therapeutic promises displayed by FGFs are worth the effort.
\end{abstract}

Keywords FGF; human lung; repair; regeneration; stem cells

\section{Some organs, such as the liver, were already recognized to regenerate since antiquity}

Regeneration was initially a theological term synonymous with rebirth. Interestingly, the concept of regeneration was already embedded in Greek mythology. Prometheus, an immortal god, who illegally gave fire and skill of metalwork to humans, was condemned to a very unusual punishment by the god Zeus. Attached firmly to a rock, each day Zeus sent an eagle to eat his liver, which would then regrow during the night only to be again eaten the next

Received July 10, 2019; accepted September 5, 2019

Correspondence: Saverio Bellusci, Saverio.Bellusci@innere.med.unigiessen.de;

Xiaokun Li, xiaokunli@wmu.edu.cn day. This torture, which was meant to be repeated over a long period of time, suggests that the liver possesses an immense capacity to regenerate. This possibility was confirmed by modern medicine; liver surgeries can lead to the removal of up to $90 \%$ of the liver, with full regrowth within several months, depending on both the age and other collateral morbidities of patients [1].

In science, the term regeneration carries the idea of functionally replacing or restoring a missing or failed organ, respectively. Most living species have, to various degrees, the possibility to regenerate. For example, the salamander can fully regrow a missing leg or tail, and this model has been extensively used to understand the molecular mechanisms involved in such a process [2]. In humans, regrowing a missing arm or a leg is regarded as impossible. However, this regenerative power is still present, to a certain extent, at the level of our fingers, most precisely at their tips. Stem cells located just below 
the nail bed can, upon sectioning of the finger's tip where the third phalange is located, assemble to form a functional structure, called the blastema. Such a structure contributes to the missing tissue and drives the regeneration process, allowing regrowth of the missing phalange [3]. However, proper regrowth by the blastema of the surrounding vascular, muscle, and nervous tissue is not evident. It is essential to note that the capacity to regrow our fingertips appears to be restricted mostly to early infancy. In general, adults do not display this regenerative capacity, and one of the underlying reasons could be that the stem cells responsible for the regrowth are either no longer functional or/and the stromal niche, which is a critical component maintaining the stem cell pool, is impaired. Modern science has added to the list of organs or tissues that harbor significant regenerative power. These include the skin, gut, and blood. Until recently, it was believed that organs such as the brain and the lung did not have regenerative capacity.

\section{Can human lungs regenerate?}

The recognition that human lungs can regenerate is quite novel. While it was previously known that rodents' lungs could regenerate after pneumonectomy [4], no reports were available to show that this was also the case in humans. In mice, the removal of the left lung leads to the rapid compensatory growth of the right lung, thereby allowing the overall lung function to reach near baseline levels (preoperative values) within three weeks [5]. Using FDG-PET (positron-emission tomography) and micro-CT (computerized tomography) scanning to investigate metabolic activity during compensatory lung growth following pneumonectomy, it was shown that after left pneumonectomy, the right lung progressively enlarged over the first three weeks [6]. The accessory (also called cardiac) lobe displayed the greatest size increase. PET/CT imaging was used to monitor metabolic activity within the individual lobes. In the cardiac lobe, 18FDG uptake (glucose analog tracer 2-deoxy-2-[18F]fluoro-d-glucose) was significantly increased in the accessory lobe at day 14 relative to preoperative values $(P<0.05)$. Interestingly, the $18 \mathrm{FDG}$ uptake in the other three right lobes (cranial, medial, and caudal) did not significantly change at any time point. Thus, compensatory growth after murine pneumonectomy occurs mostly in the accessory lobe.

After these studies in mice, a seminal paper by Butler and colleagues was published [7], demonstrating that, indeed, compensatory lung growth is also possible in humans. They reported the case of a 33-year-old woman diagnosed with lung adenocarcinoma in 1995. Her treatment involved a right-sided pneumonectomy to remove the tumor. As expected, the removal of the right lung led to a severe reduction in her lung function.
However, follow-up examinations over the next 15 years indicated that she progressively recovered almost full lung capacity. This patient had an initial FEV1 (forced expiratory volume, an essential measure of pulmonary function) of 35\% and FVC (forced vital capacity, defined as the amount of air that can be forcibly exhaled from the lungs after taking the deepest breath possible) of $49 \%$ after pneumonectomy.

During the 15 years post-operation, a progressive, constant improvement was observed. The patient's spirometry resulted in a final FEV1 of $60 \%$ and FVC of $73 \%$ (interestingly, based on aging alone, during these 15 years a $10 \%$ decline of her lung function should have been observed). Annual surveillance CT scans indicated that the size of her remaining left lung was more substantial than before. Estimation of acinar-airway dimensions by magnetic resonance imaging suggested an increase in the number of alveoli, rather than the enlargement of preexisting alveoli. Following this evidence that the human lung is capable of regeneration, a critical question remained: how are we going to integrate this vital function in the treatment of lung disease. From a clinical point of view, this relatively new concept is still not widely used to design innovative therapies to treat patients.

\section{Repairing damaged lungs ex vivo may offer a solution for the lack of suitable lungs for transplants}

One aspect linked to the newly accepted concept that human lungs can regenerate is that part of this regeneration process should also involve a tonic repair process of the existing but failing lung. A recent publication has investigated the repair potential of low-quality (damaged) donor lungs, which are usually considered non-suitable for transplantation [8]. Lung transplantation is considered the last therapeutic option for devastating end-stage lung disease. Many progresses have been made to enhance posttransplant survival. These include inducing immune tolerance and preventing infections. However, a key aspect of successful lung transplantation is the quality of the donor lung to prevent primary graft dysfunction [9]. One crucial challenge to improve the quality of the donor lungs has been the time window available to treat the lungs after removal from the deceased donors. A recent report described an elegant method to maintain a fully functional lung outside the body for over 36-56 h [8]. An advanced support system, involving a relatively old technique called cross-circulation, allowed the lungs previously damaged by ischemia/reperfusion to functionally recover, making them acceptable for lung transplants. Cross-circulation was a surgical procedure frequently used in the 1950s to allow the exchange of blood flow between two patients. Applied in the context of this study, this approach, which made use 
of the swine model, permitted long-term support of the lungs outside the body. A first priority in this study was to provide the right temperature to the explanted lung in order to mimic the conditions existing in the chest cavity. To that end, the researchers developed innovative solutions such as a humidification system with ambient temperature control and a re-circulating warm water organ basin. This system also prevented the outer surface of the lung from drying out, thereby keeping the integrity of the lung. They also improved the blood flow into and out of the lungs during cross-circulation by developing new components and techniques allowing height and hydrostatic pressure adjustments and feedback-regulated pressure-controlled flow. In addition to delivering to the lungs critical systemic and metabolic factors, this approach allowed therapeutic interventions, which aimed to restore lung function. Stem cells were used to replace defective cells with new therapeutic cells derived from the transplant recipient. Drug cocktails were also applied to improve the repair process. The authors also established image-guided techniques for the delivery of drugs and cells in specific regions of the lung without the need for repeated biopsies.

\section{Balancing lung regeneration and lung function: the welcome use of extracellular corporeal membrane oxygenation (ECMO)}

One particular challenge, when faced with severe lung diseases such as pneumonia, is that the lungs undergo drastic remodeling, with massive infiltration of immune cells in the parenchyma associated with large areas of alveolar destruction (emphysema), as well as fibrotic foci. It is clear that keeping the lungs functioning in these conditions is difficult, and may not be compatible with an efficient repair process. The use of extracellular corporeal membrane oxygenation (ECMO) in this context has proven to be efficient for patients undergoing massive lung failure [10]. In ECMO, blood from the patient is drawn through a catheter and run through a device that adds oxygen and removes the carbon dioxide and then returns the blood to the patient. During this time, the patient is exposed to a low-level ventilator, thereby allowing the lungs to move. This setting prevents the deleterious mechanical stress induced by a high-level ventilator and high oxygen concentration (the standard therapy for ARDS, when the patient is responsive). This delicate technique, which has been defined as the equivalent of dialysis for the lung, calls for the intervention of a multidisciplinary team, and bypasses the use of the lungs, allowing them to "rest" while the endogenous process of repair is taking place. Patients remain typically on ECMO for ten days, but this time can be prolonged based on their overall health conditions.

Again, the critical process at work to repair/regenerate the lungs in both in vitro and in vivo settings is the fact that stem cells are present in the adult lung. The next section will describe the different types of stem cells present in the adult lung, which are key to the repair process.

\section{Key adult endogenous stem cells needed for regeneration}

As the adult lung is relatively quiescent compared to other organs, such as the skin or the gut, it has been challenging to detect proliferative cells that could be playing the role of stem cells. The use of injury models, primarily in mice, combined with lineage tracing experiments, has allowed the identification of these cells. It has been reported that most of the epithelial cells can proliferate and differentiate into different epithelial cells following injury. These include, in the conducting airway, the basal cells [11], club cells [12-14], and variant of club cells [13,15], at the exception of the ciliated cells. In the respiratory airway, these cells include the alveolar type 2 (AT2) cells [16,17], the alveolar type 1 (AT1) cells $[18,19]$, the bronchoalveolar stem cells (BASCs) [20], and the lineage negative epithelial progenitor (LNEP) cells [21]. Fig.1 shows the position of these cells along the proximal-distal axis of the human lung. Table 1 summarizes what is known about these cells (for an extensive review see [22]). It is important to mention that while the human equivalent of these mouse epithelial stem cells have been identified, it is difficult to functionally validate these cells in human in vivo. Most of the approaches to test the property of these stem cells (self-renewal and differentiation) have been carried out using organoids (mixture of epithelial "stem" cells and mesenchymal cells grown in Matrigel, see [23]). There is therefore no direct testing of their stem cell capabilities by transplanting these cells in damaged human lungs with the goal to investigate their capacity to integrate into injured areas as well as proliferate and differentiate. Therefore, this important functional validation for these cells in human is still missing.

\section{Some adult stem cells rely on Fgf signaling for their survival, proliferation and/or differentiation}

Fibroblast growth factors (Fgfs) belong to a large superfamily of signaling molecules. Among them, the members of the Fgf7 subgroup, consisting of Fgf-1, -3, -7, -10 and -22 , act via the Fgf receptor (Fgfr) $2 b$ expressed mostly by epithelial cells [24]. Fgf signaling is mediated via the activation of PI3K- and MAPK-signaling pathways and/or activation of phospholipase $\mathrm{C} \gamma$ (Plc- $\gamma$ ). Fgfr2b-signaling leads to the growth, survival, and differentiation of epithelial cells. Fgf10/Fgfr2b signaling is critical for 


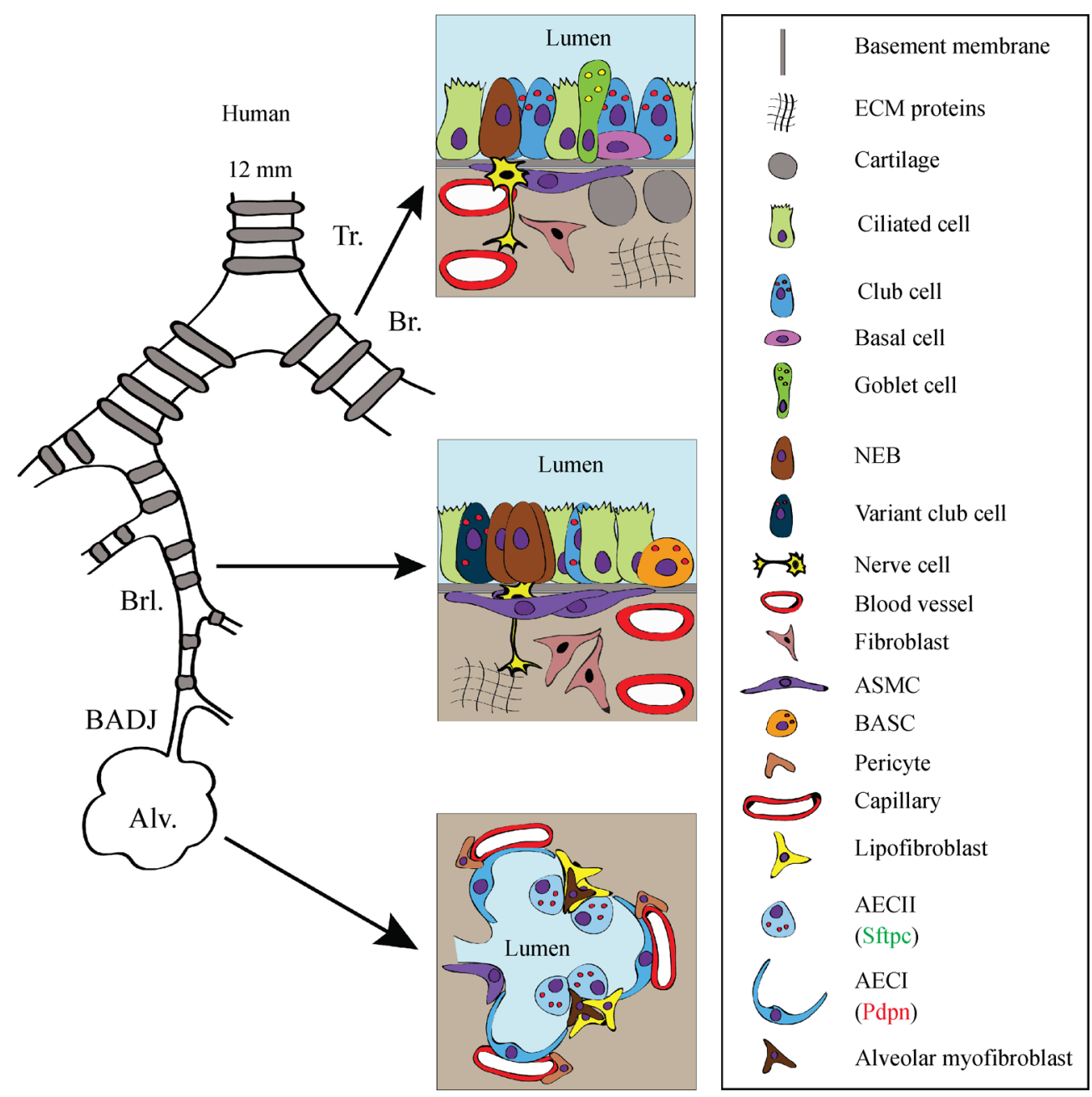

Fig. 1 Different populations of cells are located along the proximal-distal axis on the human lung (adapted from [23]).

Table 1 Key stem cells for regeneration in lung

\begin{tabular}{|c|c|c|c|c|}
\hline Stem cells & Markers & Differentiation capabilities & Lineage-tracing & Reference \\
\hline \multicolumn{5}{|l|}{ Bronchial and alveolar lineages } \\
\hline $\begin{array}{l}\text { Broncho-alveolar stem cells } \\
\text { (BASCs) }\end{array}$ & Sftoc, Scgb1a1 & BASCs, club, AT2 & $\begin{array}{l}\text { Sftpc-Dre-ERT2 and Scgb1a1- } \\
\text { CreERT2 with a new } \\
\text { reporter cassette }\end{array}$ & [20] \\
\hline Basal cells & Trp63, Krt5, Krt14, Ngfr, Pdn & Basal, club, ciliated, AT1, AT2 & Krt14-CreERT2 & [11] \\
\hline $\begin{array}{l}\text { Lineage negative epithelial } \\
\text { progenitor cells (LNEPs) }\end{array}$ & Integrin $\alpha 6$, integrin $\beta 4$ & LNEP, club, ciliated, AT1, AT2 & Sftpc-CreERT2 & [21] \\
\hline \multicolumn{5}{|l|}{ Bronchial lineages } \\
\hline Club cells & Scgb1a1, Cyp2f2 high & Club, ciliated, basal & Scgb1a1-CreERT2 & [12-14] \\
\hline Variant of club cells & Scgb1a1, Cyp2f2 low & Club, ciliated, basal & $\begin{array}{l}\text { Scgb1a1-CreERT2, } \\
\text { Upk3a-CreERT2 }\end{array}$ & {$[13,15]$} \\
\hline Basal cells & Trp63, Krt5, Krt14, Ngfr, Pdn & Basal, club, ciliated & Krt5-CreERT2, Krt14-CreERT2 & {$[61,65]$} \\
\hline \multicolumn{5}{|l|}{ Alveolar lineages } \\
\hline AT2 & Sftpc & AT2, AT1 & Sftpc-CreERT2 & {$[16,17]$} \\
\hline AT1 & Норx, Aqp5, Pdpn & AT1, AT2 & Hopx-CreERT2 & {$[18,19]$} \\
\hline
\end{tabular}


murine lung development, while Fgf7 is dispensable [2527]. There is strong evidence that Fgf signaling is key to control the formation of different epithelial lung lineages during ontogenesis. Fgf10, for example, elicits, in a dosedependent manner, the formation of the alveolar epithelial lineage. During early development, Fgf10 has been previously described to maintain the undifferentiated status of the stem cells expressing both (sex determining region Y)-box9 (Sox9) and the inhibitor of DNA binding 2 (Id2) in the distal lung epithelium. Upon inhibition of Fgf10 activity, these cells acquire the expression of Sox2, a marker of the bronchiolar lineage [28]. The use of Id2CreERT2 driver mice to lineage-trace these cells demonstrated that they give rise to all the cells in the alveolar and bronchiolar lineages. Our results also indicated that Fgf10 could play an important role not only in the proliferation but also in the differentiation of the epithelial progenitor cells toward the AT2 lineage [28]. In particular, we reported that there is an unbalanced alveolar population as the percentile of AT2 cells is decreased while the percentile of AT1 cells is increased. We also show that the expression of the AT2 cell signature is decreased in Fgflo heterozygous AT2 cells [29]. Interestingly, Fgf10 hypomorphic lungs, displaying $20 \%$ of the normal $F g f 10$ expression present in wild type (WT) lungs, also show a pronounced defect in AT2 cells, further supporting a role for Fgf10 in AT2 lineage formation [29]. The role of Fgf10 on adult AT2 cells is therefore particularly promising. Interestingly, $\mathrm{Fg} f 10$ overexpression in the adult lung leads to BASC amplification [30]. It is possible that Fgf10 could directly act on BASCs, as evidenced by single-cell RNA sequencing showing that $F g f r 2$ expression is enriched in these cells $[20,31]$. Lineage tracing of BASCs, combined with single cell RNA-seq in the context of either naphthalene or bleomycin injury, should allow the identification of the different relevant pathways activated in these cells during the repair process. Basal cells can be specifically labeled using the nerve growth factor receptor (Ngfr). This gene was drastically reduced in the $F g f l 0$ hypomorphic lungs [29], suggesting that Fgf10 was instrumental for the formation of the basal cells. Indeed, the blockade of Fgfr2b ligands, or the activation of Fgf10 signaling, led to the almost complete reduction of basal cells, or their expansion, respectively [30,32].

\section{Adult epithelial stem cells exist in the context of specific stromal niches}

Different stromal niches are associated with various types of epithelial stem cells in the distal lung (Fig. 2). Previously, we proposed that the airway smooth muscle cells (ASMCs) represent a niche for the variant of club cells. In this model, following injury, the ASMCs respond to Wnt signaling from the epithelium and start expressing

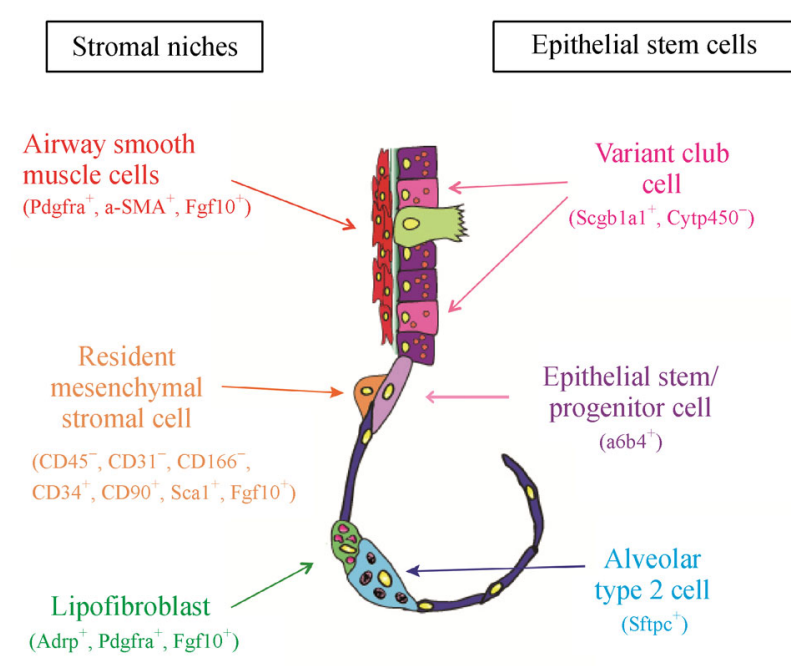

Fig. 2 Key epithelial stem cells and their associated stromal niches involved in repair/regeneration in the distal part of the human lung.

Fgf10, which will subsequently act on the variant of club cells present in the epithelium, thus facilitating their proliferation $[30,32]$. We propose that this model should be revisited, as many other cell types are intertwined with the ASMCs, such as glioma-associated oncogene homolog 1 (Gli1)-positive cells [33]. It has been proposed that upon injury, sonic hedgehog (Shh) expression from the epithelium is decreased, thereby allowing the expansion of the target cells (Gli1-positive). The role of these cells in the context of repair is not clear. In regard to the other types of stem cells present in the distal region of the lung, the BASCs interact with still to be defined stromal cells, while the LNEP interact with stem cell antigen (Sca) 1-positive resident stromal cells. Finally, the AT2 cells interact with lipofibroblasts (LIFs). Interestingly, all these stromal niches express Fgf10, suggesting that this growth factor could be crucial for the repair process. Lung stromal cells expressing platelet-derived growth factor receptor $\alpha$ (PDGFR $\alpha$ ) are instrumental for AT2 cell growth in vitro using alveolospheres. Lineage-labeled AT2 cells isolated by FACS were mixed with primary PDGFR $\alpha$-positive lung stromal cells and placed in 3D culture (Matrigel). In these conditions, these AT2 cells gave rise to self-renewing "alveolospheres," which contained both AT2s and cells expressing multiple AT1 markers [16]. This stromal population included LIFs, lipid droplet containing cells that expressed adipose related protein (ADRP), and PDGFR $\alpha$ [34-36]. LIF normally reside close to AT2s. LIF may therefore constitute a stromal niche for AT2 stem cells in the murine lung. A similar dynamic exists between AT2 and mesenchymal cells in the human lung. More recently, the Morrisey laboratory showed that these AT2 supportive cells co-express axis inhibition protein 2 
(Axin2), PDGFR $\alpha$, and Fgf7 [37]. These cells may be different from the PDGFR $\alpha$-positive Fgf10-positive LIFs, which our research group is focusing on.

LIFs are lipid-containing alveolar interstitial fibroblasts. These cells are becoming increasingly recognized as an important component of the AT2 stem cell niche in the rodent lung. Although the function of LIFs was initially described to assist AT2 cells in surfactant production, recent evidence suggests that these cells are also crucial for survival and growth of epithelial stem cells. We have recently investigated their cellular origin, as well as the pathways controlling their formation, during lung development.

A population of lipid-droplet-containing stromal cells emerges in the developing mouse lung between embryonic day 15.5 and E16.5 [34]. This is associated with the upregulation, in the lung mesenchyme, of three important genes involved in lipogenesis, namely, Adrp (a marker of mature LIFs), peroxisome proliferator-activated receptor $\gamma$ (Ppary) (master switch of lipogenesis) and Fgf10 (previously shown to identify a subpopulation of lipofibroblast progenitors). In addition, while only a subpopulation of total embryonic LIFs derives from Fgf1 $0^{\text {pos }}$ progenitor cells, the knockdown of Fgfr2b ligand activity in vivo, as well as the reduction in FgflO expression, led to a global reduction in the expression levels of LIF markers at E18.5. The analysis of Fgfrlb knockouts, as well as mutants with conditional partial inactivation of $F g f r 2 b$ in the lung mesenchyme, shows that both receptors are involved in LIFs formation, suggesting a possible compensation between these two receptors. We also reported the expression of FGF10 and $A D R P$ in human fetal lungs over time. We proposed that Fgf10 signaling plays a key role in the formation of LIFs during late lung development. One important pathological process to consider is what is happening to the stromal niche when the corresponding epithelial stem cells are damaged, either acutely or chronically. In the context of acute damage to the AT2 cells using bleomycin (resulting in lung fibrosis), we previously reported that the LIFs give rise to activated myofibroblasts (MYFs) [38]. We also reported, using in vivo lineage tracing tools, that lineage-labeled activated MYFs give rise to LIFs during the resolution of fibrosis [38]. Please see a comprehensive review of the role of mesenchymal stem cells in fibrosis formation [39].

\section{FGF10 deficiency is associated with human lung disease}

Two human syndromes, namely, the aplasia of lacrimal and salivary glands (ALSG) and the lacrimo-auriculo-dentodigital syndrome (LADD), are associated with heterozygous mutations in the human $F G F 10$ or FGFR2B genes, respectively $[40,41]$. In particular, IVC, FEV1, and the corresponding FEV1/IVC ratio were significantly lower in patients with loss of FGF10 functional heterozygosity compared to both non-carrier siblings and predicted reference values [42]. These data are consistent with the diagnostic of chronic obstructive pulmonary disease. In humans, exposure to inflammation is known to increase the risk of developing broncho-pulmonary dysplasia (BPD) [43]. BPD develops in babies born prematurely and is characterized by impaired alveolar development. Consistent with the presence of high inflammation in the lungs of babies with BPD, it has been demonstrated that interactions between nuclear factor $\kappa \mathrm{B}(\mathrm{NF}-\kappa \mathrm{B})$, specificity protein $1(\mathrm{Sp} 1)$, and $\mathrm{Sp} 3$ led to inhibition of Fgflo expression [44]. Fgf10 inhibition is mediated by activation of Toll-like receptors 2 and 4 (Tlr2 or Tlr4), and a decrease in FGF10 concentration is found in lung samples from children with BPD [45]. The molecular mechanisms linking inflammatory signaling and FGF10, an important developmental gene that might play a role in BPD pathogenesis, are still elusive.

\section{Pre-clinical (rodent) models indicating that recombinant FGF10 can be used to repair and regenerate human lungs}

We previously reported that canonical wingless-related integration site (Wnt)-signaling works downstream of Fgf signaling $[28,46,47]$. Interestingly, exposure to bleomycin in mice displaying an epithelial-specific deletion of $\beta$ catenin-signaling ( $\beta$-catenin is downstream of both Fgfand Wnt-signaling) led to increased fibrosis [48]. In the mouse model, previous studies focused primarily on the beneficial effect of treatment with Palifermin, a truncated form of keratinocyte growth factor (KGF, also known as FGF-7) [49,50]. While KGF demonstrated an apparent protective effect, genetic $F g f l 0$ overexpression postbleomycin injury resulted in increased survival, as well as prevention and accelerated resolution of lung fibrosis in mice [51]. Interestingly, established IPF therapies which target tyrosine kinases (e.g., nintedanib), would also inhibit FGF signaling, and this may lead to detrimental effects. There is, therefore, an urgent need to define the role of endogenous FGF signaling in IPF.

Because of the beneficial effects of exogenous Fgfr2b ligands on lung repair, we hypothesized that endogenous Fgfr2b ligands play an essential role in repair following bleomycin injury. However, we found that the expression of Fgfr2b ligands and receptors were decreased after bleomycin injury in wild type mice [52]. In the same study, we reported that inhibition of the activity of endogenous Fgfr $2 b$ ligands during bleomycin-induced lung injury did not lead to significantly increased fibrosis or decreased survival. These results do not negate the potential benefit of exogenously stimulating developmental pathways to 
protect against lung fibrosis.

Fgf10 is also involved in the regeneration of the bronchial lung epithelium after naphthalene injury [30]. We recently published that Fgf10-Hippo epithelialmesenchymal crosstalk maintains and recruits lung basal stem cells in the conducting airways [32]. In this paper, we showed that, while transient $F g f 10$ expression by ASMCs is critical for proper airway epithelial regeneration in response to injury, sustained Fgf10 secretion by the ASMC niche, in response to chronic integrin-like kinase (Ilk)/ Hippo inactivation, results in pathological changes in airway architecture. Fgf10/Fgfr2b signaling may, therefore, be an interesting therapeutic target to treat chronic lung diseases.

Influenza virus (IV)-mediated pneumonia often leads to severe damage to the lung epithelium and impairment of respiratory functions. We have previously described the importance of Fgf signaling in enhancing stem/progenitor cell-mediated regenerative responses. Importantly, we have reported that a highly pathogenic IV preferentially infects an epithelial cell subset characterized by high proliferative capacity and defined by $\mathrm{EpCam}{ }^{\text {high }} \mathrm{CD} 24^{\text {low }}$ integrin $(\alpha 6)^{\text {high }}$. These cells are also positive for Sca1 and are highly enriched in the lung stem cell pool previously characterized by the signature integrin $(\beta 4)^{+} \mathrm{CD} 200^{+}$. We used 3-dimensional organoid cultures derived from these epithelial stem/progenitor cells (EpiSPC), and in vivo infection models including transgenic mice, to show that their proliferation and the maintenance of the epithelial barrier after IV-induced injury required Fgfr2b signaling. IV-infected EpiSPC displayed decreased renewal capacity due to the IV-induced blockade of $\beta$-catenin-dependent Fgfr2b signaling. Therapeutic application of FGF10 intratracheally led to increased recruitment of non-infected EpiSPC for tissue regeneration and was associated with enhanced proliferative potential, restoration of alveolar barrier function, and increased survival following IV pneumonia [53]. Furthermore, Fgf10 delivery to the distal lung may represent a putative therapy to enhance regeneration in the context of acute respiratory distress.

\section{FGF7 clinical trial for acute respiratory distress syndrome (ARDS): lessons learnt for future clinical trials}

Mortality linked to ARDS remains unacceptably high, underscoring the fact that no efficient pharmacological therapy exists despite intense basic and clinical research. FGF7 seemed initially to be perfectly suited for ARDS treatment. Various pre-clinical studies in animals demonstrated its efficacy in enhancing the repair mechanisms following experimental acute lung injury [54]. Interestingly, FGF7 expression in human lungs is suppressed in early ARDS [55]. In addition, it was shown that FGF7 enhances alveolar epithelial sodium ion $\left(\mathrm{Na}^{+}\right)$transport processes, thereby allowing the efficient clearance of alveolar edema [56], which is required for the survival of patients with ARDS. Moreover, in a recent clinical trial, 36 healthy volunteers received intravenously-administered FGF7 (60 $\mu \mathrm{g} / \mathrm{kg}$ per day), or placebo for three days before inhalation of lipopolysaccharide (LPS) to trigger acute lung injury [57]. The analysis of the bronchoalveolar lavage fluid samples of these patients collected $6 \mathrm{~h}$ after LPS inhalation indicated that pre-treatment with FGF7 increased the concentrations of anti-inflammatory cytokines and markers of alveolar epithelial type II cell proliferation. These data suggest that systemic exposure to FGF7 is well tolerated and, most importantly, has an effect on the alveolar epithelium. Interestingly, FGF7 was also efficient in treating patients with oral mucositis as a consequence of radiotherapy and chemotherapy [58]. This was likely the rationale to use the same concentration, frequency, and duration of FGF7 treatment in a recent clinical trial aiming to characterize, in patients with ARDS, the impact of intravenously-administered FGF7 [59]. In the prospective, double-blind, randomized, allocation-concealed, placebo-controlled phase $2 \mathrm{KARE}$ trial, 60 patients with moderate-to-severe ARDS were included. The oxygenation index at day 7 was assessed as the primary outcome. This readout is a reliable predictor of therapy success in ARDS, as it takes into consideration both gas exchange and respiratory mechanics. The study demonstrated that FGF7 did not ameliorate any of the primary clinical and physiologic outcomes assessed. Even though the trial was not properly designed to evaluate secondary readouts such as the duration of ventilation, mortality, or the length of intensive-care unit stay, the results do suggest that these secondary outcomes became worse in the experimental group receiving FGF7. The authors concluded that FGF7 should not be used for the treatment of ARDS patients.

It is to be noted that in the context of this study, conclusions about the negative impact of FGF7 on the clinical outcomes are difficult to assess as the trial was not designed to assess the secondary readouts and also because the mortality in the placebo group was surprisingly lower than expected for this patient cohort. The lack of effects of FGF7 on ARDS patients could be due to different reasons. First, there is no evidence that the dose and route of FGF7 administration used in this trial were optimal to act on the damaged alveolar epithelium. In addition, in the human LPS inhalation clinical study [57], the alveolar epithelium was healthy at the time of FGF7 treatment, while the diseased lungs in ARDS patients likely displayed both under-ventilated and non-ventilated lung areas. This may have had a negative impact in the context of FGF7 treatment as the damaged areas are likely less perfused than healthy regions of the lung. It is therefore possible that the level of FGF7 in these areas was too low to trigger a 
clear biological effect within the time frame of the trial. In addition, systemic concentrations of FGF7 may have been too high, triggering some of the negative effects observed during the trial.

It is worth to mention that in most animal pre-clinical studies assessing the effect of FGF7 in acute lung injury, the growth factor was supplied directly to the lungs either by inhalation or instillation. The translation to the human situation may not be easy; even though drug inhalation for patients with ARDS might be useful when targeting macrophages [60], it is not clear whether poorly or nonventilated areas can be effectively reached. Failure to do so could be the underlying cause behind the failure in clinical trials for ARDS of various promising pharmacological treatments. In the future, optimizing delivery protocols to deliver efficiently the drugs at the alveolar level will be crucial.

\section{Looking toward the future: rationale to use FGF10 instead of FGF7 for clinical trials}

While FGF7 was historically thought to be a potent FGF to enhance the repair/regeneration process, FGF10 has emerged as a more relevant growth factor for clinical use for different reasons. First, evidence in mice shows that Fgf10, and not Fgf7, is the growth factor used by the lung for its development. FgflO inactivation leads to lung agenesis, while $\mathrm{Fgf7}$ null mice have no distinct lung phenotype [26,62]. Second, Fgf10 is the endogenous growth factor used by the lung to act on key epithelial stem cells (basal cells, a variant of club cells, epiSPC and AT2) for the regeneration process. Third, even though FGF7 and FGF10 can act via the same receptor, they elicit different biological responses (proliferation vs. migration, respectively). The molecular bases for this difference were first reported by our research group [63]. Fourth, FGF10 does not induce directly epithelial proliferation but works by modulating cell-cell and cell-extracellular matrix adhesion [28]. Therefore, FGF10 may be safer to use compared to FGF7 in the clinical context. Indeed, our recently published data indicate that in early development, the transcription of $\mathrm{G}$ protein-coupled receptor class $\mathrm{C}$ group 5 member A (Gprc5a), a gene coding a $\mathrm{G}$ protein-coupled receptor acting as an anti-oncogene, is induced by Fgfl0. Inactivation of Gprc5a in mice leads to lung adenocarcinoma [64]. So Fgf10, via the induction of Gprc5a, as well as other genes previously described in Jones et al. [28] may prevent cancer formation.

In conclusion, with the recent evidence that the human lung both repairs and regenerates and with the characterization of the crucial corresponding stem cells, fibroblast growth factors are ideally suited to act on these cells to promote repair and regeneration. In the future, clinical trials must be tailored to allow local delivery to the damaged lungs.

\section{Acknowledgements}

We would like to thank Matthew Jones for the critical reading of this manuscript. Saverio Bellusci is supported by the Cardio-Pulmonary Institute and by grants from the Deutsche Forschungsgemeinschaft (DFG; Nos. BE4443/1-1, BE4443/4-1, BE4443/6-1, KFO309 P7, and SFB1213-projects A02 and A04). Jin-San Zhang is partially supported by start-up packages from Whenzhou Medical University and Wenzhou University. Xiaokun Li is partially funded by the National Key R\&D Program of China (No. 2017YFA0506000). Chengshui Chen and Chaolei Chen are funded by the National Natural Science Foundation of China (Nos. 81570075, 81770074, 81600062).

\section{Compliance with ethics guidelines}

Xuran Chu, Chengshui Chen, Chaolei Chen, Jin-San Zhang, Saverio Bellusci, and Xiaokun Li declare that they have no conflict of interest. This manuscript is a review article and does not involve a research protocol requiring approval by the relevant institutional review board or ethics committee.

\section{References}

1. Nagasue N, Yukaya H, Ogawa Y, Kohno H, Nakamura T. Human liver regeneration after major hepatic resection. A study of normal liver and livers with chronic hepatitis and cirrhosis. Ann Surg 1987; 206(1): 30-39

2. McCusker C, Bryant SV, Gardiner DM. The axolotl limb blastema: cellular and molecular mechanisms driving blastema formation and limb regeneration in tetrapods. Regeneration (Oxf) 2015; 2(2): 5471

3. Simkin J, Sammarco MC, Dawson LA, Schanes PP, Yu L, Muneoka $\mathrm{K}$. The mammalian blastema: regeneration at our fingertips. Regeneration (Oxf) 2015; 2(3): 93-105

4. Tatár-Kiss S, Bardócz S, Kertai P. Changes in L-ornithine decarboxylase activity in regenerating lung lobes. FEBS Lett 1984; 175(1): 131-134

5. Ad hoc Statement Committee, American Thoracic Society. Mechanisms and limits of induced postnatal lung growth. Am J Respir Crit Care Med 2004; 170(3): 319-343

6. Gibney BC, Park MA, Chamoto K, Ysasi A, Konerding MA, Tsuda A, Mentzer SJ. Detection of murine post-pneumonectomy lung regeneration by 18FDG PET imaging. EJNMMI Res 2012; 2(1): 48

7. Butler JP, Loring SH, Patz S, Tsuda A, Yablonskiy DA, Mentzer SJ. Evidence for adult lung growth in humans. N Engl J Med 2012; 367 (3): 244-247

8. Guenthart BA, O’Neill JD, Kim J, Queen D, Chicotka S, Fung K, Simpson M, Donocoff R, Salna M, Marboe CC, Cunningham K, Halligan SP, Wobma HM, Hozain AE, Romanov A, VunjakNovakovic G, Bacchetta M. Regeneration of severely damaged lungs using an interventional cross-circulation platform. Nat Commun 2019; 10(1): 1985 
9. Meyer KC.Recent advances in lung transplantation. F1000Res 2018; 7. pii: F1000 Faculty Rev-1684

10. Hardin CC, Hibbert K. ECMO for severe ARDS. N Engl J Med 2018; 378(21): 2032-2034

11. Kumar PA, Hu Y, Yamamoto Y, Hoe NB, Wei TS, Mu D, Sun Y, Joo LS, Dagher R, Zielonka EM, Wang Y, Lim B, Chow VT, Crum $\mathrm{CP}$, Xian W, McKeon F. Distal airway stem cells yield alveoli in vitro and during lung regeneration following H1N1 influenza infection. Cell 2011; 147(3): 525-538

12. Perl AK, Wert SE, Loudy DE, Shan Z, Blair PA, Whitsett JA. Conditional recombination reveals distinct subsets of epithelial cells in trachea, bronchi, and alveoli. Am J Respir Cell Mol Biol 2005; 33 (5): 455-462

13. Rawlins EL, Okubo T, Xue Y, Brass DM, Auten RL, Hasegawa H, Wang F, Hogan BL. The role of Scgb1a1 + Clara cells in the longterm maintenance and repair of lung airway, but not alveolar, epithelium. Cell Stem Cell 2009; 4(6): 525-534

14. Tata PR, Mou H, Pardo-Saganta A, Zhao R, Prabhu M, Law BM, Vinarsky V, Cho JL, Breton S, Sahay A, Medoff BD, Rajagopal J. Dedifferentiation of committed epithelial cells into stem cells in vivo. Nature 2013; 503(7475): 218-223

15. Guha A, Vasconcelos M, Cai Y, Yoneda M, Hinds A, Qian J, Li G, Dickel L, Johnson JE, Kimura S, Guo J, McMahon J, McMahon AP, Cardoso WV. Neuroepithelial body microenvironment is a niche for a distinct subset of Clara-like precursors in the developing airways. Proc Natl Acad Sci USA 2012; 109(31): 12592-12597

16. Barkauskas CE, Cronce MJ, Rackley CR, Bowie EJ, Keene DR, Stripp BR, Randell SH, Noble PW, Hogan BL. Type 2 alveolar cells are stem cells in adult lung. J Clin Invest 2013; 123(7): 3025-3036

17. Desai TJ, Brownfield DG, Krasnow MA. Alveolar progenitor and stem cells in lung development, renewal and cancer. Nature 2014; 507(7491): 190-194

18. Jain R, Barkauskas CE, Takeda N, Bowie EJ, Aghajanian H, Wang Q, Padmanabhan A, Manderfield LJ, Gupta M, Li D, Li L, Trivedi CM, Hogan BLM, Epstein JA. Plasticity of $\mathrm{Hopx}^{+}$type I alveolar cells to regenerate type II cells in the lung. Nat Commun 2015; 6(1): 6727

19. Wang Y, Tang Z, Huang H, Li J, Wang Z, Yu Y, Zhang C, Li J, Dai H, Wang F, Cai T, Tang N. Pulmonary alveolar type I cell population consists of two distinct subtypes that differ in cell fate. Proc Natl Acad Sci USA 2018; 115(10): 2407-2412

20. Liu Q, Liu K, Cui G, Huang X, Yao S, Guo W, Qin Z, Li Y, Yang R, $\mathrm{Pu}$ W, Zhang L, He L, Zhao H, Yu W, Tang M, Tian X, Cai D, Nie Y, Hu S, Ren T, Qiao Z, Huang H, Zeng YA, Jing N, Peng G, Ji H, Zhou B. Lung regeneration by multipotent stem cells residing at the bronchioalveolar-duct junction. Nat Genet 2019; 51(4): 728-738

21. Chapman HA, Li X, Alexander JP, Brumwell A, Lorizio W, Tan K, Sonnenberg A, Wei Y, Vu TH. Integrin $\alpha 6 \beta 4$ identifies an adult distal lung epithelial population with regenerative potential in mice. J Clin Invest 2011; 121(7): 2855-2862

22. Kotton DN, Morrisey EE. Lung regeneration: mechanisms, applications and emerging stem cell populations. Nat Med 2014; 20(8): 822-832

23. Gkatzis K, Taghizadeh S, Huh D, Stainier DYR, Bellusci S. Use of three-dimensional organoids and lung-on-a-chip methods to study lung development, regeneration and disease. Eur Respir J 2018; 52 : 1800876
24. Ornitz DM, Itoh $\mathrm{N}$. The fibroblast growth factor signaling pathway. Wiley Interdiscip Rev Dev Biol 2015; 4(3): 215-266

25. Bellusci S, Grindley J, Emoto H, Itoh N, Hogan BL. Fibroblast growth factor 10 (FGF10) and branching morphogenesis in the embryonic mouse lung. Development 1997; 124(23): 4867-4878

26. Guo L, Degenstein L, Fuchs E. Keratinocyte growth factor is required for hair development but not for wound healing. Genes Dev 1996; 10(2): 165-175

27. Ohuchi H, Hori Y, Yamasaki M, Harada H, Sekine K, Kato S, Itoh N. FGF10 acts as a major ligand for FGF receptor 2 IIIb in mouse multi-organ development. Biochem Biophys Res Commun 2000; 277(3): 643-649

28. Jones MR, Dilai S, Lingampally A, Chao CM, Danopoulos S, Carraro G, Mukhametshina R, Wilhelm J, Baumgart-Vogt E, Al Alam D, Chen C, Minoo P, Zhang JS, Bellusci S. A comprehensive analysis of fibroblast growth factor receptor $2 \mathrm{~b}$ signaling on epithelial tip progenitor cells during early mouse lung branching morphogenesis. Front Genet 2019a; 9: 746

29. Chao CM, Yahya F, Moiseenko A, Tiozzo C, Shrestha A, Ahmadvand N, El Agha E, Quantius J, Dilai S, Kheirollahi V, Jones M, Wilhem J, Carraro G, Ehrhardt H, Zimmer KP, Barreto G, Ahlbrecht K, Morty RE, Herold S, Abellar RG, Seeger W, Schermuly R, Zhang JS, Minoo P, Bellusci S. Fgf10 deficiency is causative for lethality in a mouse model of bronchopulmonary dysplasia. J Pathol 2017; 241(1): 91-103

30. Volckaert T, Dill E, Campbell A, Tiozzo C, Majka S, Bellusci S, De Langhe SP. Parabronchial smooth muscle constitutes an airway epithelial stem cell niche in the mouse lung after injury. J Clin Invest 2011; 121(11): 4409-4419

31. Jones M, Zhang JS, Bellusci S. Bronchioalveolar stem cells vindicated! Biotarget 2019; 3: 4

32. Volckaert T, Yuan T, Chao CM, Bell H, Sitaula A, Szimmtenings L, El Agha E, Chanda D, Majka S, Bellusci S, Thannickal VJ, Fässler R, De Langhe SP. Fgf10-Hippo epithelial-mesenchymal crosstalk maintains and recruits lung basal stem cells. Dev Cell 2017; 43(1): 48-59.e45

33. Peng T, Frank DB, Kadzik RS, Morley MP, Rathi KS, Wang T, Zhou S, Cheng L, Lu MM, Morrisey EE. Hedgehog actively maintains adult lung quiescence and regulates repair and regeneration. Nature 2015; 526(7574): 578-582

34. Al Alam D, El Agha E, Sakurai R, Kheirollahi V, Moiseenko A, Danopoulos S, Shrestha A, Schmoldt C, Quantius J, Herold S, Chao CM, Tiozzo C, De Langhe S, Plikus MV, Thornton M, Grubbs B, Minoo P, Rehan VK, Bellusci S. Evidence for the involvement of fibroblast growth factor 10 in lipofibroblast formation during embryonic lung development. Development 2015; 142(23): 41394150

35. Ntokou A, Klein F, Dontireddy D, Becker S, Bellusci S, Richardson WD, Szibor M, Braun T, Morty RE, Seeger W, Voswinckel R, Ahlbrecht K. Characterization of the platelet-derived growth factor receptor- $\alpha$-positive cell lineage during murine late lung development. Am J Physiol Lung Cell Mol Physiol 2015; 309(9): L942L958

36. Ntokou A, Szibor M, Rodríguez-Castillo JA, Quantius J, Herold S, El Agha E, Bellusci S, Salwig I, Braun T, Voswinckel R, Seeger W, Morty RE, Ahlbrecht K. A novel mouse Cre-driver line targeting Perilipin 2-expressing cells in the neonatal lung. Genesis 2017; 55 


\section{(12): e23080}

37. Zepp JA, Zacharias WJ, Frank DB, Cavanaugh CA, Zhou S, Morley MP, Morrisey EE. Distinct mesenchymal lineages and niches promote epithelial self-renewal and myofibrogenesis in the lung. Cell 2017; 170: 1134-1148.e1110

38. El Agha E, Moiseenko A, Kheirollahi V, De Langhe S, Crnkovic S, Kwapiszewska G, Szibor M, Kosanovic D, Schwind F, Schermuly RT, Henneke I, MacKenzie B, Quantius J, Herold S, Ntokou A, Ahlbrecht K, Braun T, Morty RE, Günther A, Seeger W, Bellusci S. Two-way conversion between lipogenic and myogenic fibroblastic phenotypes marks the progression and resolution of lung fibrosis. Cell Stem Cell 2017b; 20: 261-273.e263

39. El Agha E, Kramann R, Schneider RK, Li X, Seeger W, Humphreys $\mathrm{BD}$, Bellusci S. Mesenchymal stem cells in fibrotic disease. Cell Stem Cell 2017a; 21(2): 166-177

40. Entesarian M, Matsson H, Klar J, Bergendal B, Olson L, Arakaki R, Hayashi Y, Ohuchi H, Falahat B, Bolstad AI, Jonsson R, WahrenHerlenius M, Dahl N. Mutations in the gene encoding fibroblast growth factor 10 are associated with aplasia of lacrimal and salivary glands. Nat Genet 2005; 37(2): 125-127

41. Rohmann E, Brunner HG, Kayserili H, Uyguner O, Nürnberg G, Lew ED, Dobbie A, Eswarakumar VP, Uzumcu A, UlubilEmeroglu M, Leroy JG, Li Y, Becker C, Lehnerdt K, Cremers CW, Yüksel-Apak M, Nürnberg P, Kubisch C, Schlessinger J, van Bokhoven H, Wollnik B. Mutations in different components of FGF signaling in LADD syndrome. Nat Genet 2006; 38(4): 414-417

42. Klar J, Blomstrand P, Brunmark C, Badhai J, Håkansson HF, Brange CS, Bergendal B, Dahl N. Fibroblast growth factor 10 haploinsufficiency causes chronic obstructive pulmonary disease. J Med Genet 2011; 48(10): 705-709

43. Klinger G, Levy I, Sirota L, Boyko V, Lerner-Geva L, Reichman B; Israel Neonatal Network. Outcome of early-onset sepsis in a national cohort of very low birth weight infants. Pediatrics 2010; 125(4): e736-e740

44. Carver BJ, Plosa EJ, Stinnett AM, Blackwell TS, Prince LS. Interactions between $\mathrm{NF}-\kappa \mathrm{B}$ and SP3 connect inflammatory signaling with reduced FGF-10 expression. J Biol Chem 2013; 288(21): 15318-15325

45. Benjamin JT, Smith RJ, Halloran BA, Day TJ, Kelly DR, Prince LS. FGF-10 is decreased in bronchopulmonary dysplasia and suppressed by Toll-like receptor activation. Am J Physiol Lung Cell Mol Physiol 2007; 292(2): L550-L558

46. Danopoulos S, Parsa S, Al Alam D, Tabatabai R, Baptista S, Tiozzo C, Carraro G, Wheeler M, Barreto G, Braun T, Li X, Hajihosseini MK, Bellusci S. Transient inhibition of FGFR2b-ligands signaling leads to irreversible loss of cellular $\beta$-catenin organization and signaling in AER during mouse limb development. PLoS One 2013; 8(10): e76248

47. Nelson WJ, Nusse R. Convergence of Wnt, $\beta$-catenin, and cadherin pathways. Science 2004; 303(5663): 1483-1487

48. Tanjore H, Degryse AL, Crossno PF, Xu XC, McConaha ME, Jones BR, Polosukhin VV, Bryant AJ, Cheng DS, Newcomb DC, McMahon FB, Gleaves LA, Blackwell TS, Lawson WE. $\beta$-catenin in the alveolar epithelium protects from lung fibrosis after intratracheal bleomycin. Am J Respir Crit Care Med 2013; 187 (6): 630-639

49. Deterding RR, Havill AM, Yano T, Middleton SC, Jacoby CR,
Shannon JM, Simonet WS, Mason RJ. Prevention of bleomycininduced lung injury in rats by keratinocyte growth factor. Proc Assoc Am Physicians 1997; 109(3): 254-268

50. Sugahara K, Iyama K, Kuroda MJ, Sano K. Double intratracheal instillation of keratinocyte growth factor prevents bleomycininduced lung fibrosis in rats. J Pathol 1998; 186(1): 90-98

51. Gupte VV, Ramasamy SK, Reddy R, Lee J, Weinreb PH, Violette SM, Guenther A, Warburton D, Driscoll B, Minoo P, Bellusci S. Overexpression of fibroblast growth factor-10 during both inflammatory and fibrotic phases attenuates bleomycin-induced pulmonary fibrosis in mice. Am J Respir Crit Care Med 2009; 180 (5): 424-436

52. MacKenzie B, Henneke I, Hezel S, Al Alam D, El Agha E, Chao CM, Quantius J, Wilhelm J, Jones M, Goth K, Li X, Seeger W, Königshoff M, Herold S, Rizvanov AA, Günther A, Bellusci S. Attenuating endogenous Fgfr2b ligands during bleomycin-induced lung fibrosis does not compromise murine lung repair. Am J Physiol Lung Cell Mol Physiol 2015; 308(10): L1014-L1024

53. Quantius J, Schmoldt C, Vazquez-Armendariz AI, Becker C, El Agha E, Wilhelm J, Morty RE, Vadász I, Mayer K, Gattenloehner S, Fink L, Matrosovich M, Li X, Seeger W, Lohmeyer J, Bellusci S, Herold S. Influenza virus infects epithelial stem/progenitor cells of the distal lung: impact on Fgfr2b-driven epithelial repair. PLoS Pathog 2016; 12(6): e1005544

54. Crosby LM, Waters CM. Epithelial repair mechanisms in the lung. Am J Physiol Lung Cell Mol Physiol 2010; 298(6): L715-L731

55. Chandel NS, Budinger GR, Mutlu GM, Varga J, Synenki L, Donnelly HK, Zirk A, Eisenbart J, Jovanovic B, Jain M. Keratinocyte growth factor expression is suppressed in early acute lung injury/acute respiratory distress syndrome by smad and c-Abl pathways. Crit Care Med 2009; 37(5): 1678-1684

56. Matthay MA, Ware LB, Zimmerman GA. The acute respiratory distress syndrome. J Clin Invest 2012; 122(8): 2731-2740

57. Shyamsundar M, McAuley DF, Ingram RJ, Gibson DS, O'Kane D, McKeown ST, Edwards A, Taggart C, Elborn JS, Calfee CS, Matthay MA, O'Kane CM. Keratinocyte growth factor promotes epithelial survival and resolution in a human model of lung injury. Am J Respir Crit Care Med 2014; 189(12): 1520-1529

58. Spielberger R, Stiff P, Bensinger W, Gentile T, Weisdorf D, Kewalramani T, Shea T, Yanovich S, Hansen K, Noga S, McCarty J, LeMaistre CF, Sung EC, Blazar BR, Elhardt D, Chen MG, Emmanouilides C. Palifermin for oral mucositis after intensive therapy for hematologic cancers. N Engl J Med 2004; 351(25): 2590-2598

59. McAuley DF, Cross LM, Hamid U, Gardner E, Elborn JS, Cullen KM, Dushianthan A, Grocott MP, Matthay MA, O'Kane CM. Keratinocyte growth factor for the treatment of the acute respiratory distress syndrome (KARE): a randomised, double-blind, placebocontrolled phase 2 trial. Lancet Respir Med 2017; 5(6): 484-491

60. Herold S, Hoegner K, Vadász I, Gessler T, Wilhelm J, Mayer K, Morty RE, Walmrath HD, Seeger W, Lohmeyer J. Inhaled granulocyte/macrophage colony-stimulating factor as treatment of pneumonia-associated acute respiratory distress syndrome. Am J Respir Crit Care Med 2014; 189(5): 609-611

61. HongKU, Reynolds SD, Watkins S, Fuchs E, Stripp BR. Basal cells are a multipotent progenitor capable of renewing the bronchial epithelium. Am J Pathol 2004; 164(2): 577-588 
62. Sekine K, Ohuchi H, Fujiwara M, Yamasaki M, Yoshizawa T, Sato T, Yagishita N, Matsui D, Koga Y, Itoh N, Kato S. Fgfl0 is essential for limb and lung formation. Nat Genet 1999; 21(1): 138-141

63. Francavilla C, Rigbolt KT, Emdal KB, Carraro G, Vernet E, BekkerJensen DB, Streicher W, Wikström M, Sundström M, Bellusci S, Cavallaro U, Blagoev B, Olsen JV. Functional proteomics defines the molecular switch underlying FGF receptor trafficking and cellular outputs. Mol Cell 2013; 51(6): 707-722

64. Zhou H, Rigoutsos I. The emerging roles of GPRC5A in diseases. Oncoscience 2014; 1(12): 765-776

65. Rock JR, Onaitis MW, Rawlins EL, Lu Y, Clark CP, Xue Y, Randell SC, Hogan LM. Basal cells as stem cells of the mouse trachea and human airway epithelium. Proc Natl Acad Sci U S A 2009; 106(31): 12771-12775 